\title{
Synthesis and Characterization of Silver and Gold Nanoparticles Using Aqueous Extract of Seaweed, Turbinaria conoides, and Their Antimicrofouling Activity
}

\author{
Sri Ramkumar Vijayan, ${ }^{1}$ Prakash Santhiyagu, ${ }^{2}$ Muthukkumarasamy Singamuthu, ${ }^{3}$ \\ Natarajan Kumari Ahila, ${ }^{4}$ Ravindran Jayaraman, ${ }^{5}$ and Kannapiran Ethiraj ${ }^{4}$ \\ ${ }^{1}$ Department of Oceanography and Coastal Area Studies, School of Marine Sciences, Alagappa University, \\ Thondi Campus, Thondi, Tamil Nadu 623 409, India \\ ${ }^{2}$ SRM Research Institute, SRM University, Kattankulathur, Kancheepuram, Tamil Nadu 603 203, India \\ ${ }^{3}$ Department of Nanoscience and Technology, Alagappa University, Karaikudi, Tamil Nadu 630 003, India \\ ${ }^{4}$ Department of Zoology, Directorate of Distance Education, Alagappa University, Karaikudi, Tamil Nadu 630 003, India \\ ${ }^{5}$ Biological Oceanography Division, CSIR-National Institute of Oceanography, Dona Paula, Goa 403 004, India
}

Correspondence should be addressed to Kannapiran Ethiraj; piran_k@yahoo.co.uk

Received 9 August 2013; Accepted 5 December 2013; Published 3 February 2014

Academic Editors: C. Boyer, A. M. Noreddin, M. Rai, and P. Webster

Copyright (C) 2014 Sri Ramkumar Vijayan et al. This is an open access article distributed under the Creative Commons Attribution License, which permits unrestricted use, distribution, and reproduction in any medium, provided the original work is properly cited.

Silver and gold nanoparticles were synthesized using an aqueous extract of the seaweed Turbinaria conoides and their antibiofilm activity against marine biofilm forming bacteria is reported here. The UV-Vis spectra showed the characteristics SPR absorption band for Ag NPs at 421 and for Au NPs at $538 \mathrm{~nm}$. Further, the synthesized nanoparticles were characterized using FT-IR, XRD, FESEM, EDX, and HRTEM analysis. Spherical and triangular nanostructures of the Ag and Au nanoparticles were observed between the size ranges of 2-17 nm and 2-19 nm, respectively. The synthesized Ag NPs are efficient in controlling the bacterial biofilm formation; however, Au NPs did not show any remarkable antibiofilm activity. The maximum zone of inhibition was recorded against E. coli $(17.6 \pm 0.42 \mathrm{~mm})$, followed by Salmonella sp., S. liquefaciens, and A. hydrophila. The macrotube dilution method inferred the MIC $\left(20-40 \mu \mathrm{L} \mathrm{mL}^{-1}\right)$ and MBC $\left(40-60 \mu \mathrm{L} \mathrm{mL}^{-1}\right)$ of Ag NPs. The CLSM images clearly showed the weak adherence and disintegrating biofilm formation of marine biofilm bacterial strains treated with Ag NPs. The Artemia cytotoxicity assay recorded the $\mathrm{LC}_{50}$ value of $88.914 \pm 5.04 \mu \mathrm{L} \mathrm{mL}^{-1}$. Thus the present study proved the efficiency of Ag NPs as a potent antimicrofouling agent and became the future perspective for the possible usage in the biofouling related issues in the aquaculture installations and other marine systems.

\section{Introduction}

Natural and artificial substrata immersed in the aquatic environment are quickly colonized by micro- and macroorganisms; this phenomenon is known as "Biofouling" [1]. Biofouling is a sequence of processes initialized by the attachment of microbes to a solid support by producing extracellular polymeric substances and thus promoting the development of a biofilm matrix. It depends upon an interaction between the bacterial cells, surface attachment, and surrounding medium [2-5]. The biofilm formation further favours the attachment of other macrofoulers $[6,7]$. These biofouling processes affect marine installations such as ship's hull, oil rigs, mariculture cages, underwater pipelines, heat exchangers, and seawater intake systems $[8,9]$. It possesses serious problems, such as corrosion, weight increase, surface alteration and distortion of the submerged structures, and speed reduction and increased fuel consumption up to $40 \%$ [10], which also 
contributes to additional $\mathrm{CO}_{2}$ emissions. Thus, the economic loss is stupendous in preventing and removing the fouling organism.

Numerous antibiofouling measures such as mechanical, chemical, and biological methods are in practice but their effects on the biofouling are not remarkable. In addition, the commercially available antifouling paints such as tributyltin (TBT) and copper sulphate are highly toxic to the nontarget aquatic organisms [11]. The TBT contributes to the development of antimicrobial tolerance and imposex or pseudohermaphroditism in marine invertebrates [12].

Application of antifouling compounds from natural sources is considered as one of the best replacement options for the most successful antifouling processes [13]. A wide variety of marine natural products from seagrasses, seaweeds, mangroves, coral reefs, and their associated organisms proved to be an excellent source of bioactive compounds and a wide range of secondary metabolites, many of which exhibited a broad spectrum of antifouling activity against marine biofilm forming microbes, algal spore adherence, mussel (phenoloxidase activity), and barnacles to artificial substratum [14-16].

Comparing the above antifoulers, "nano materials" are efficient in inhibiting the bacterial adhesion and biofilm formation due to their effective antimicrobial property and large specific surface area, which is inversely proportional to their particle size. Silver, copper, zinc, and magnesium fluoride nanoparticles were having good antimicrobial properties and also reduced the cell adhesion and destabilized the biofilm matrix $[17,18]$. Earlier reports demonstrated that $\mathrm{ZnO}, \mathrm{CuO}$, and Ag nanoparticles (NPs) coated on solid surfaces inhibit the biofilm formation $[19,20]$ and particularly Ag NPs act as potential antimicrobial agents against different microorganisms $[21,22]$. There are several methods to synthesize the nanoparticles, but the greener method is more advantageous as it is cost effective, energy efficient, and does not involve the use of more chemicals, thus is an ecofriendly and reliable method [23].

Seaweeds are macrophytic marine algae that produce a great variety of secondary metabolites having broad spectrum of biological activities. So far, several researchers reported the synthesis of nanoparticles using seaweeds $[24,25]$ and their biological applications [26-29]. However, reports on the marine antimicrofouling property of biologically synthesized silver and gold nanoparticles are scanty. Hence, the present study was carried out to understand the antibiofilm activity against marine biofilm forming bacteria and Artemia cytotoxicity of biosynthesized silver nanoparticles (Ag NPs) and gold nanoparticles (Au NPs) using the aqueous extract of seaweed Turbinaria conoides.

\section{Materials and Methods}

2.1. Chemicals. Silver nitrate $\left(\mathrm{AgNO}_{3} ; \mathrm{Merck}\right.$, India) and chloroauric acid ( $\mathrm{HAuCl}_{4} \cdot 3 \mathrm{H}_{2} \mathrm{O}$; Sigma Aldrich, USA) were used in this study. All the microbiological media and chemicals were obtained from HiMedia Laboratories, India. Ultrapure Milli Q water was used throughout the study.
2.2. Collection of Seaweed. The brown seaweeds, Turbinaria conoides (J. Agardh, Kutzing, 1860), were collected from Mandapam coastal region $\left(78^{\circ} 8^{\prime} \mathrm{E}, 9^{\circ} 17^{\prime} \mathrm{N}\right)$, Gulf of Mannar, Southeast coast of India. They were washed thoroughly with running tap water followed by distilled water to remove adhering salts and associated biota. The washed samples were dried under shade at room temperature for a week. The dried materials were ground to fine powder using mixer grinder.

2.3. Preparation of Aqueous Extract and Synthesis of Ag and $A u$ NPs. $5 \mathrm{~g}$ of the seaweed powder was boiled with $100 \mathrm{~mL}$ of sterile deionised water for 10-15 min and filtered through Whatman number 1 filter paper. The resultant aqueous filtrate was treated individually with $90 \mathrm{~mL}$ aqueous solution of $(1 \mathrm{mM}) \quad \mathrm{AgNO}_{3}$ and $\mathrm{HAuCl}_{4} \cdot 3 \mathrm{H}_{2} \mathrm{O}$. The mixture was incubated at room temperature and the color change in the reaction solution was noted by visual observation.

2.4. Characterization of $A g$ and $A u$ NPs. Surface plasmon resonance (SPR) absorption bands were measured using a UV-Visible spectrophotometer (UV-1800 Shimadzu, Japan) by scanning operated at a resolution of $1 \mathrm{~nm}$, between 200 and $800 \mathrm{~nm}$. The crystal structure of the Ag and Au NPs was characterized by the X-ray diffraction (XRD) pattern using X'Pert PRO analytical X-ray diffractometer operating at a voltage of $45 \mathrm{kV}$ in the current of $40 \mathrm{~mA}$ using $\mathrm{Cu}$ $\mathrm{K} \alpha$ radiation with $\mathrm{X}$ 'Pert High Score Plus Software. The Fourier Transform Infrared (FT-IR-Nicolet Thermo spectrophotometer iS5, USA) spectra of seaweed extract and synthesized Ag and Au NPs colloidal solutions were analyzed in the range between 4000 and $400 \mathrm{~cm}^{-1}$ with a resolution of $4 \mathrm{~cm}^{-1}$ to arrive at the possible functional groups responsible for reduction and capping behaviour of biomolecules present in the seaweed extracts. A drop of colloidal nanoparticles were coated on a copper plate, dried in a hot air oven, and examined using Field Emission Scanning Electron Microscopy (FESEM) (Carl Zeiss, Germany) equipped with Energy Dispersive X-ray spectroscopy (EDX-JEOL, JSM5610) analysis. Morphology and size of the nanoparticles were further authenticated by the HRTEM image. A drop of $\mathrm{Ag}$ and $\mathrm{Au}$ NPs were coated on a carbon coated copper grid of 200 mesh size and dried for $5 \mathrm{~min}$ prior to the observation in a High Resolution Transmission Electron Microscope (HRTEM) (JEOL JEM 2100 HRTEM) operated at an accelerating voltage of $200 \mathrm{kV}$. The selected area electron diffraction (SAED) pattern was also performed.

\subsection{Antibacterial and Antibiofilm Assay against Marine Biofilm Bacterial Strains}

2.5.1. Selection of Marine Biofilm Forming Bacterial Strains. Four different marine biofilm forming bacterial strains, namely, Salmonella sp. (JN596113), E. coli (JN585664), S. liquefaciens (JN596115), and A. hydrophila (JN561697) isolated by Prakash (2012, unpublished data) from different substratum and immersed in Thondi coastal waters, Palk Bay, Southeast coast of India, were used to study the antibiofilm activity of the synthesized Ag and Au NPs. 


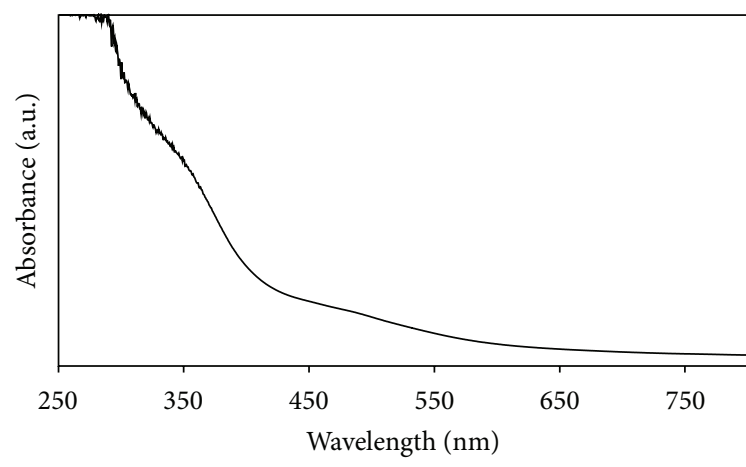

(a)

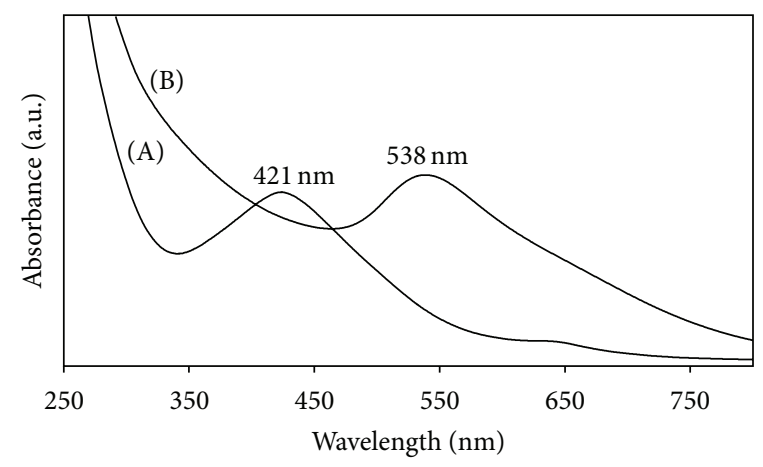

(b)

Figure 1: (a) UV-Vis spectrum of T. conoides extract; (b) synthesized colloidal Ag NPs (A) and Au NPs (B).

2.5.2. Antibacterial Potential of $A g$ and $A u$ NPs. Antibacterial activity of the synthesized Ag and Au NPs screened against marine biofilm bacterial strains using agar well diffusion method [30, 31]. In brief, all the biofilm bacterial strains were individually inoculated in the Zobell marine broth and incubated for $12 \mathrm{~h}$. The biofilm bacterial cells $\left(\sim 1 \times 10^{8}\right.$ cells $\mathrm{mL}^{-1}$ ) were inoculated using sterile cotton swabs on the Mueller Hinton Agar plates prepared with 50\% seawater. Experimental wells of $6 \mathrm{~mm}$ diameters on the plates were loaded with $50 \mu \mathrm{L}$ of colloidal nanoparticles; the sterilized distilled water was used as a negative control and incubated for $24 \mathrm{~h}$ at $37^{\circ} \mathrm{C}$. The assay was carried out in triplicates. The zone of inhibition was measured from the well to the edge of the clear zone in millimetre $(\mathrm{mm})$.

2.5.3. Minimum Inhibitory Concentration (MIC) and Minimum Bactericidal Concentration (MBC) of NPs. The MIC and $\mathrm{MBC}$ of the NPs were determined according to the method of Ruparelia et al. [31] with some modification. Forty microlitres $\left(\sim 1 \times 10^{8}\right.$ cells $\left.\mathrm{mL}^{-1}\right)$ of each biofilm forming bacterial strains were added individually to $4 \mathrm{~mL}$ of Zobell marine broth $(\mathrm{ZMB})$. The different concentrations $(5,10,20$, $40,60,80$, and $100 \mu \mathrm{L}$ ) of the NPs solutions were added to the test tubes containing the test strains. After $24 \mathrm{~h}$ of incubation, the MIC results were noted by checking the turbidity of the bacterial growth and the MBC were determined by streaking a loop full of the bacterial culture on the Zobell marine Agar (ZMA) plates, incubated at $37^{\circ} \mathrm{C}$ for $24 \mathrm{~h}$. The $\mathrm{MBC}$ is the concentration at which the bacteria are completely killed.

2.5.4. Confocal Laser Scanning Microscopic (CLSM) Analysis. The effect of biosynthesized Ag and Au NPs on the adherence and biofilm formation were observed under a Confocal Laser Scanning Microscope (Carl Zeiss, LSM 710). In concise, the presterilized glass slides of $1 \mathrm{~cm} \times 1 \mathrm{~cm}$ each were placed in the 24-well polystyrene plates containing (total volume$2.5 \mathrm{~mL}) 2.3 \mathrm{~mL}$ of sterilized Zobell marine broth, $60 \mu \mathrm{L}$ of Ag NPs, and $100 \mu \mathrm{L}$ of test biofilm bacterial strains ( 1.5 $\times 10^{8}$ cells $\mathrm{mL}^{-1}$ ), incubated at $37^{\circ} \mathrm{C}$. The respective strains without the NPs were considered as a negative control. After $24 \mathrm{~h}$ of incubation, the glass slides were taken carefully and washed with PBS (Phosphate Buffer Solution) to remove the loosely attached bacterial cells. Each glass slide was stained with $0.1 \%$ acridine orange and examined in the CLSM at a magnification of $63 \mathrm{x}$. The $488 \mathrm{~nm}$ argon laser and a 500-640 $\mathrm{nm}$ band pass emission filter were used to excite and detect the stained cells. The Z-stack analysis (surface topography and 3D architecture) was calculated using Zen 2009 software [32].

2.6. Cytotoxicity and Anticrustacean Assay. Cytotoxicity assay is one of the easiest screening assays to test the toxicity of bioactive materials. Here, we used Artemia salina as the test organisms. It is one of the major marine biofouling organism belonging to Crustaceous. The larvae (I instar) of A. salina hatched out as described by Harwig and Scott [33]. For the toxicity test, varying concentrations of $40,60,80,100,120$, 140 , and $160 \mu \mathrm{L} \mathrm{mL}^{-1}$ of the NPs solution were transferred to the 24-well plates containing $1 \mathrm{~mL}$ of sterilized seawater [34]. The live nauplii of $A$. salina (10 nauplii per well) were added to it and incubated at $25^{\circ} \mathrm{C}$. Seawater without the NPs was the control. After $24 \mathrm{~h}$ of incubation, surviving A. salina larvae were counted in each well.

2.7. Statistical Analysis. The data generated were expressed as a mean $\pm \mathrm{SD}$. The analysis of variance (one-way ANOVA; $P<0.05)$ was performed for the mean value of antibacterial properties of Ag NPs against marine biofilm bacterial strains. The percentage mortality of $A$. salina larvae in the different test concentrations of the Ag NPs and the negative control was compared by Dunnett test with varied significant levels $(P<0.0001 ; P<0.01)$. All the analyses were carried out using SPSS v16.0 (SPSS Inc., USA). Profit analysis of the toxicity data was calculated with EPA profit analysis software ver.1.5, USA.

\section{Results and Discussion}

3.1. UV-Visible Spectrum. The UV-Vis spectrum observed at $421 \mathrm{~nm}$ and $538 \mathrm{~nm}$ confirmed the synthesis of $\mathrm{Ag}$ and $\mathrm{Au}$ NPs, respectively (Figure 1(b) (A and B)). The UV-Vis spectrum of seaweed $T$. conoides aqueous extract has shown 
no significant peaks (Figure 1(a)). After the addition of $T$. conoides extract with the colourless silver nitrate and yellow coloured chloroauric acid the solutions were changed to characteristic reddish brown and ruby-red colour provided a convenient excitation of SPR, which indicates the formation of $\mathrm{Ag}$ and $\mathrm{Au}$ NPs $[35,36]$. The present study also observed the rapid synthesis of Ag and Au NPs within 15-20 and 10-15 minutes, respectively.

3.2. X-Ray Diffraction Patterns. The X-ray diffraction patterns of the Ag and Au NPs synthesized using T. conoides extract are shown in Figures 2(a) and 2(b). Presence of four distinct high diffraction peaks at $38.1^{\circ}, 44.2^{\circ}, 64.3^{\circ}$, and $77.3^{\circ}$, respectively, indexing the Bragg's reflection planes (111), (200), (220), and (311) (JCPDS No. 04-0783) confirmed the face-centered cubic silver. Similarly, the XRD pattern of the $\mathrm{Au}$ NPs showed a strong diffraction peak at $38.1^{\circ}$ attributed to (111) facet of the face-centered cubic metal gold structure. The other three diffraction peaks $\left(44.3^{\circ}, 64.5^{\circ}\right.$, and $77.5^{\circ}$ for the facets of (200), (220), and (311) (JCPDS File number 040784)) were also detected. Thus, the XRD results revealed that the Ag and Au NPs were formed by the reduction of the metal ions by $T$. conoides extract was crystalline in nature. Similar structures of the Ag and Au NPs were synthesized using terrestrial plants reported earlier by Chandran et al. [37] and Philip and Unni [38].

3.3. Fourier Transform Infrared Spectrum. The FT-IR spectrum of T. conoides extract, the colloidal Ag NPs and Au NPs, envisages that the molecular arrangement of different functional groups (Figures 3(a)-3(c)). When all the three transmission peaks were compared, the suppressed/increased peaks in the colloidal solutions were due to the consequence of metal nanoparticles bound to bioorganic molecules. The shifted peaks such as 3441 and $1629 \mathrm{~cm}^{-1}$ were characteristics of $\mathrm{O}-\mathrm{H}$ and $\mathrm{C}=\mathrm{O}$ stretching modes due to a free hydroxyl group and a carboxylic acid group, respectively. Another band at $1020 \mathrm{~cm}^{-1}$ could be assigned to the $\mathrm{C}-\mathrm{OH}$ vibrations of primary alcohol groups in the extracts. It is evident through the FT-IR spectra that the presence of different functional groups in the aqueous seaweed extract might serve as the reducing and capping agents of the Ag and Au NPs. Similar phenomenon was also observed by some authors to identify the possible biomolecules responsible for the reduction and capping of the Ag and Au NPs synthesized using other seaweeds [39].

3.4. Field Emission Scanning Electron Microscopic Analysis. The FESEM images distinguished the spherical and triangular morphology of the Ag and Au NPs with the size less than $60 \mathrm{~nm}$ (Figures 4(a) and 4(b)). Size distribution analysis of the capped $\mathrm{Ag}$ and $\mathrm{Au}$ nanoconjugates confirmed that the particles were well dispersed. The qualitative and quantitative analysis by the EDX revealed the highest proportion of $\mathrm{Ag}$ and $\mathrm{Au}$ signals (Figures 4(c) and 4(d)). Minor peaks of the copper and carbon were observed that could be the biomolecules bound to the surface of the NPs and the copper used for coating the samples.

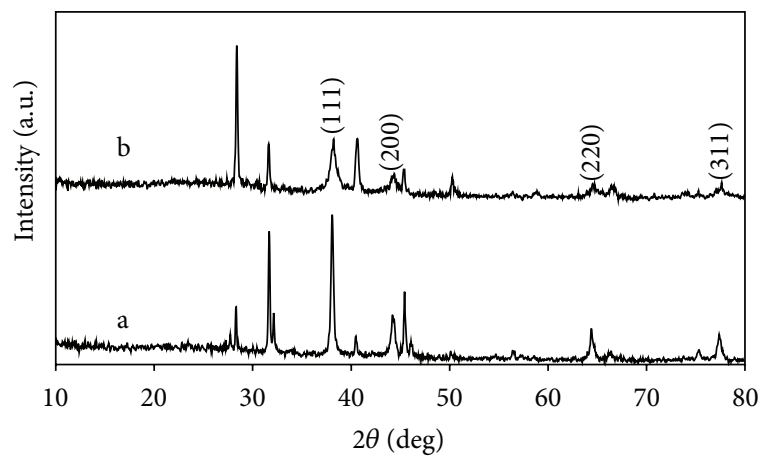

Figure 2: XRD patterns of Ag NPs (a) and Au NPs (b).

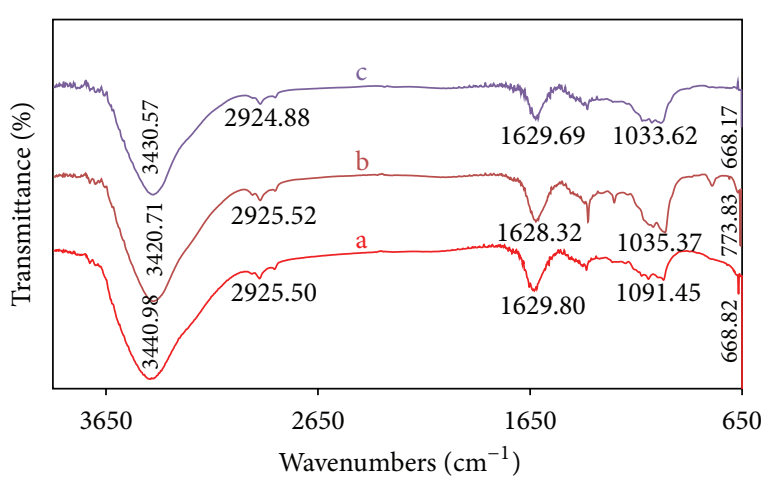

Figure 3: FT-IR spectra of T. conoides extract (a), Ag NPs (b), and $\mathrm{Au} \mathrm{NPs} \mathrm{(c).}$

3.5. High Resolution Transmission Electron Microscopic Studies. In addition, the HRTEM provided further insight into the morphology and sizes of the Ag and Au NPs. The NPs were well dispersed and no agglomeration was noticed. The uniformly small sized spherical and fascinating triangular shaped nanoparticles of the sizes ranging between 2-17 nm and 2-19 nm of the Ag NPs and Au NPs (Figures 5(a) and 5(b)), respectively, were microscopically visualized. These narrow ranged sizes of nanoparticles agreed with the SPR results. The crystalline nature of $\mathrm{Ag}$ and $\mathrm{Au}$ NPs was evidenced by the SAED pattern (Figure $5 \mathrm{a}(\mathrm{C})$ and $5(\mathrm{~b})(\mathrm{C})$ ) with bright circular rings corresponding to Bragg's reflection planes of (111), (200), (220), and (311) [40]. Thus, the SAED pattern also supported the XRD pattern of the present study.

3.6. Antibacterial Activity, MIC, and MBC Values of Ag NPs. The Ag NPs exhibited good antibacterial property, whereas the $\mathrm{Au}$ NPs did not show any inhibitory activity against the marine biofilm forming bacterial strains. Hence, the Ag NPs were screened for further investigation. The zone of inhibition against the marine biofilm forming bacterial strains ranged between $12.3 \pm 0.47$ and $15.6 \pm 0.42 \mathrm{~mm}$ (Table 1$)$. The maximum zone of inhibition $(15.6 \pm 0.42 \mathrm{~mm}$ ) was registered against E. coli, followed by Salmonella sp. (14.5 $\pm 0.41 \mathrm{~mm})$ $>$ S. liquefaciens $(13.2 \pm 0.62 \mathrm{~mm})>$ A. hydrophila $(12.3 \pm$ $0.47 \mathrm{~mm}$ ). However, the macrotube dilution method inferred the MIC (20-40 $\left.\mu \mathrm{L} \mathrm{mL}^{-1}\right)$ and MBC (40-60 $\left.\mu \mathrm{L} \mathrm{mL}^{-1}\right)$ value 


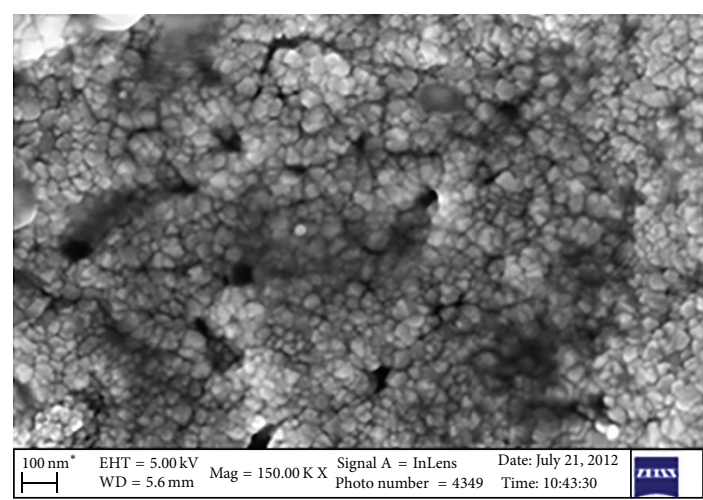

(a)

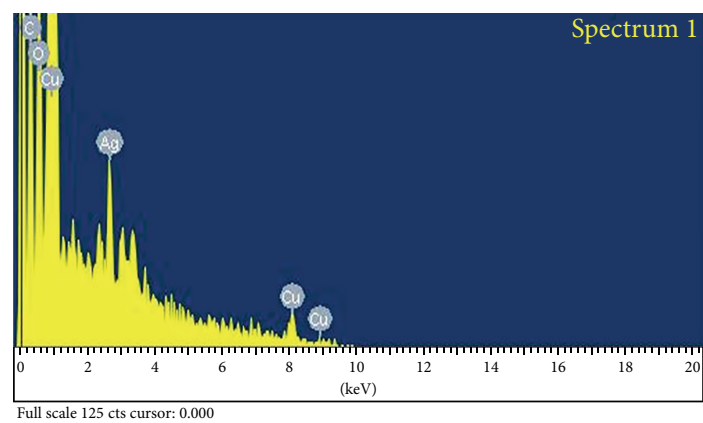

(c)

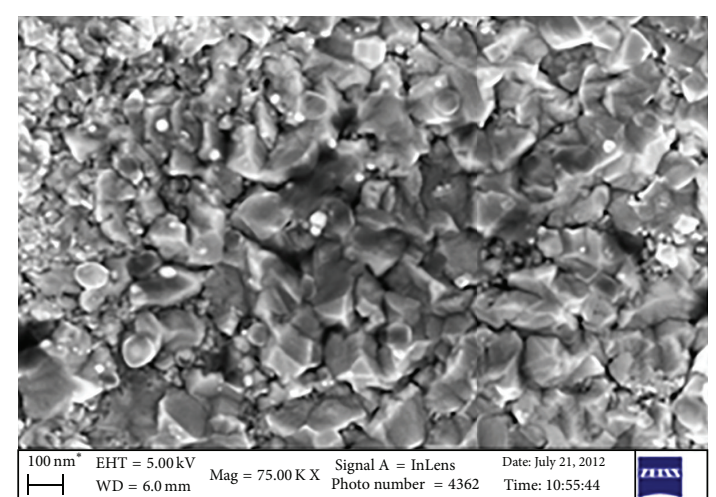

(b)

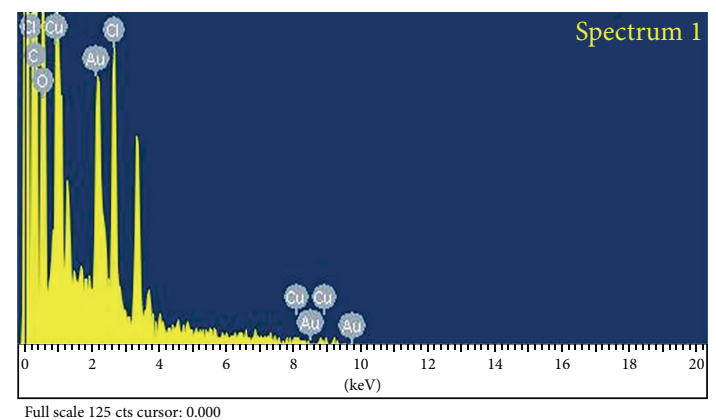

(d)

Figure 4: FESEM image of Ag (a) and Au NPs (b) with EDX graph of Ag (c) and Au (d).

TABLE 1: In vitro antibacterial potential of biosynthesized Ag NPs using T. conoides extract against marine biofilm forming bacterial isolates.

\begin{tabular}{lccc}
\hline Test organisms & Agar well diffusion assay $(\mathrm{mm})$ & $\mathrm{MIC}\left(\mu \mathrm{L} \mathrm{mL}^{-1}\right)$ & $\mathrm{MBC}\left(\mu \mathrm{L} \mathrm{mL} \mathrm{mL}^{-1}\right)$ \\
\hline Salmonella sp. & $14.5 \pm 0.41$ & 20 & 40 \\
E. coli & $15.6 \pm 0.42$ & 20 & 40 \\
S. liquefaciens & $13.2 \pm 0.62$ & 40 & 60 \\
A. hydrophila & $12.3 \pm 0.47$ & 40 & 60
\end{tabular}

Values \pm SD indicate the three individual experiments.

of the Ag NPs (Table 1). The least inhibitory concentration $\left(20 \mu \mathrm{L} \mathrm{mL}^{-1}\right)$ was recorded against E. coli and Salmonella sp., whereas the highest bactericidal concentration $\left(60 \mu \mathrm{L} \mathrm{mL}^{-1}\right)$ was reported to inhibit all the bacterial strains tested. The T. conoides mediated Ag NPs are thus proved to reduce the bacterial densities significantly even at the least concentration. Sondi and Salopek-Sondi [41] reported that the Ag NPs disrupt the bacterial cells by alteration of the permeability of the cell membrane and finally cause the cell death. The size and shape of the nanoparticles play an important role in many pharmaceutical applications. The rapidly synthesised Ag NPs was identified between 2 and $17 \mathrm{~nm}$ with spherical shape, which gives better results compared with the Ag NPs synthesized using other plant materials [42], mangroves [43], seaweeds [27, 28], and coastal bacterial strains [44]. The present study supports that the Ag NPs synthesized using aqueous extract of $T$. conoides was found to be a potent source of antifoulant inhibiting the growth of marine biofilm forming bacteria.
3.7. Confocal Laser Scanning Microscopic Analysis. At $24 \mathrm{~h}$ of incubation, the CLSM image (Figure 6) depicted the weak adherence and disintegrated biofilm architecture of the test bacterial strains, that is, Salmonella sp., E. coli, S. liquefaciens, and $A$. hydrophila. In control, strong adhering ability of marine biofilm bacterial strains which led to the development of dense biofilm formation on the glass pieces was observed. Thus, the CLSM study confirmed that a substantial concentration of the Ag NPs were active in controlling the adherence and biofilm formation [45]. Prabhawathi et al. [19] also reported that the greener synthesis of protein stabilized Ag NPs coated on the surface of the polycaprolactam (polymer) proved to be a good antifouling agent against bacterial and fungal pathogens. The same technique was adopted earlier to measure the biofilm inhibition and adherences against Streptococcus pyogenes [46], Staphylococcus aureus [47, 48], and E. coli PHL628 [49] using different bacterial extracts. The nanoparticles precoated on the surfaces, surfactants, and enzymes inhibited the bacterial biofilm formation [50, 

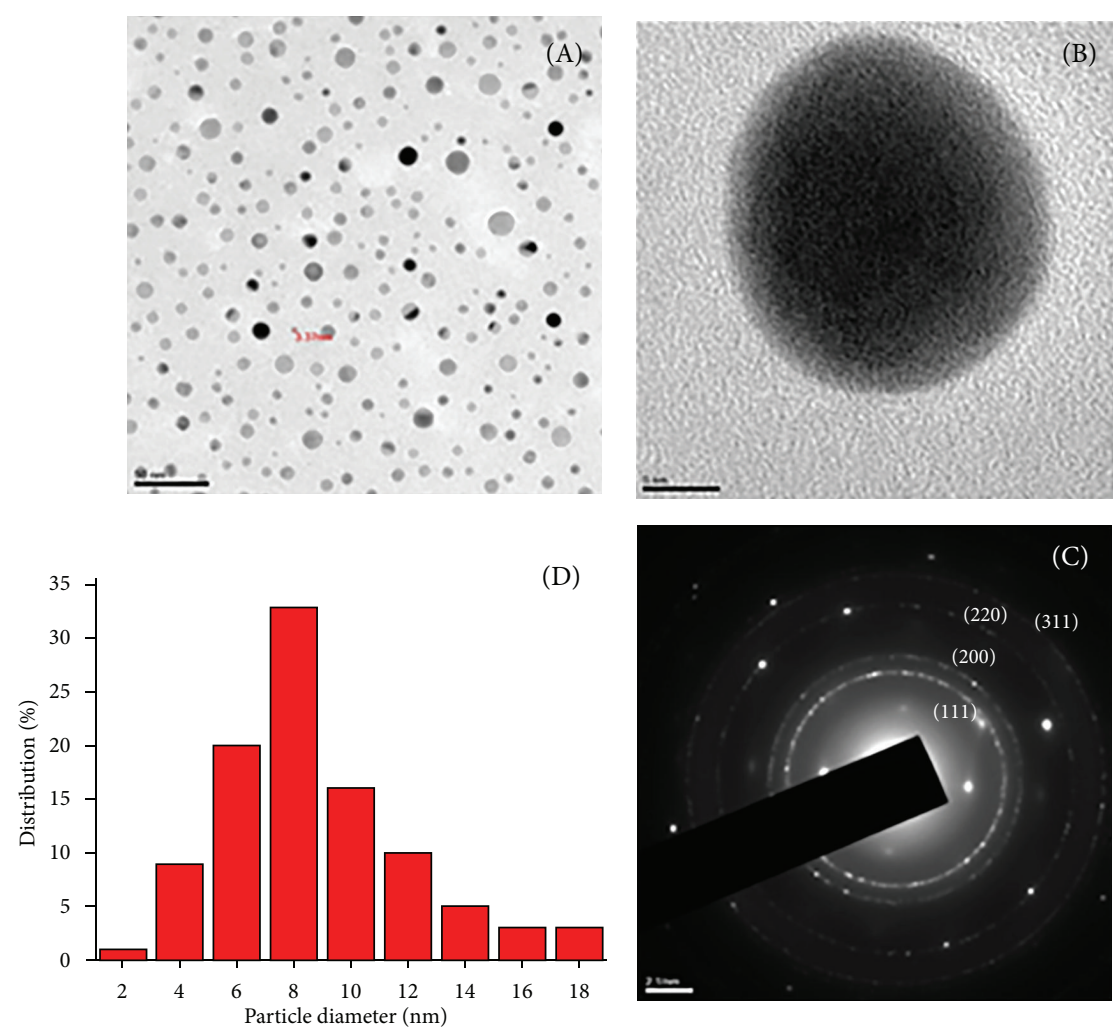

(a)

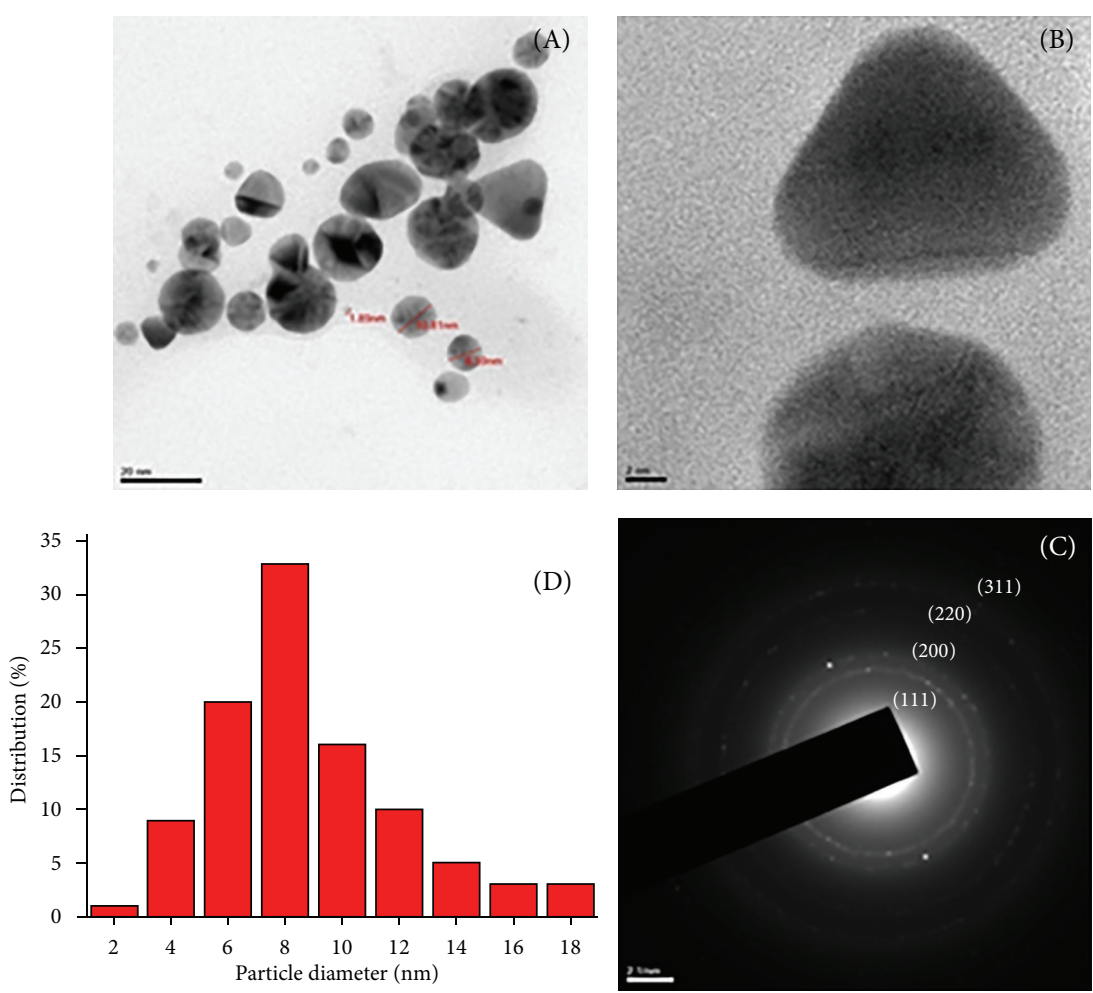

(b)

FIGURE 5: HRTEM images of Ag NPs (a) and Au NPs (b); different magnifications (A) and (B); SAED pattern (C); particle size distribution (D). 

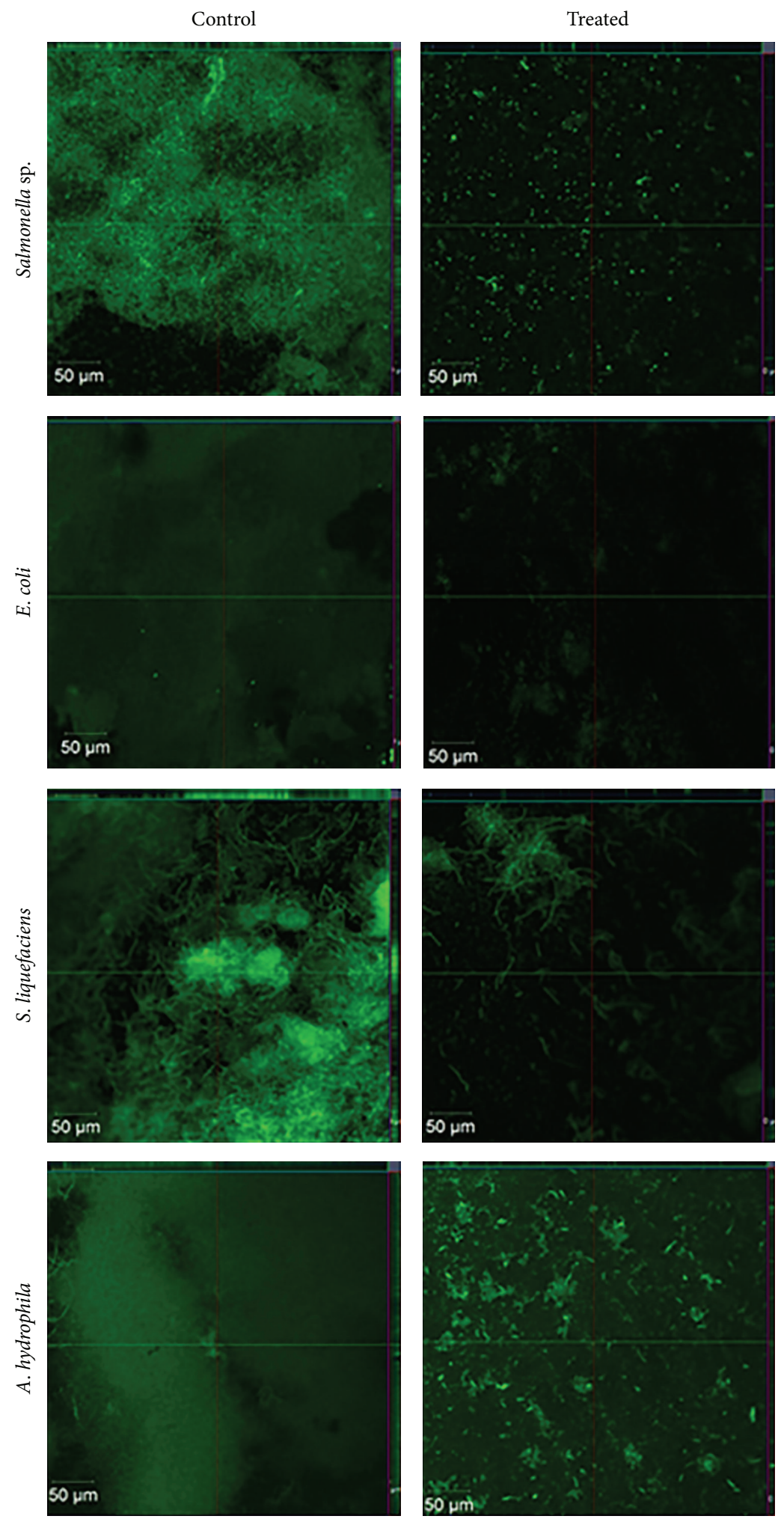

FiguRE 6: CLSM images representing the antibiofilm activity of Ag NPs against marine biofilm forming isolates of Salmonella sp., E. coli, $S$. liquefaciens, and A. hydrophila. 


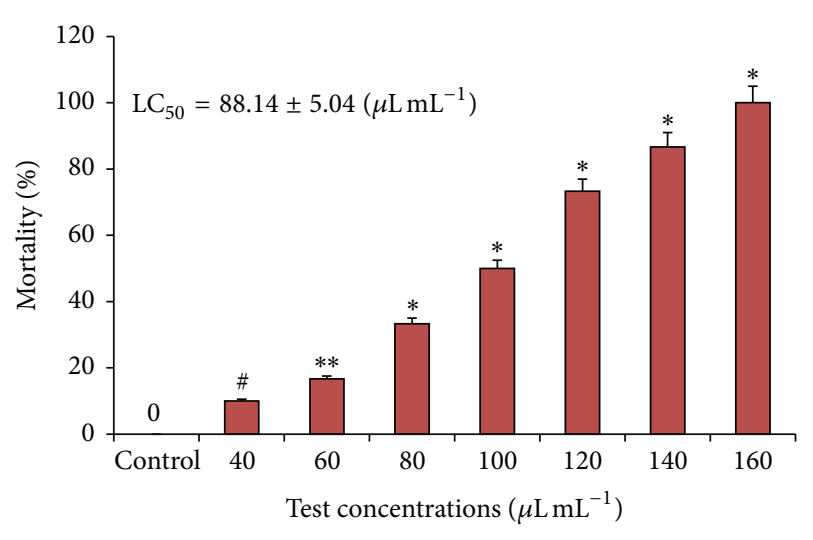

FIgURE 7: Cytotoxicity of Ag NPs on Artemia salina: increased concentration of Ag NPs $(0-160 \mu \mathrm{L} / \mathrm{mL})$ (X-axis) mortality of the larvae up to $100 \%$ ( $Y$-axis); all the data were expressed in mean \pm SD of three replicates. ${ }^{*} P<0.0001$ and ${ }^{* *} P<0.01$ indicate statistical significance; ${ }^{\#} \mathrm{NS}$ (not significant).

51]. Therefore, CLSM observations supported the antibiofilm property of Ag NPs strongly as one of the potent antifouling agents against marine biofilm formation under in vitro conditions.

3.8. Cytotoxicity and Anticrustacean Properties of Ag NPs. The Artemia cytotoxicity and anticrustacean assays are one of the reliable methods to screen and detect the cytotoxicity of the products. The $\mathrm{LC}_{50}$ values on the cytotoxicity of the synthesized colloidal Ag NPs was $88.91 \pm 5.04 \mu \mathrm{LL}^{-1}$, whereas the highest mortality was observed at $160 \mu \mathrm{L} \mathrm{mL}^{-1}$ concentration. Lethality was found to be directly proportional to the concentration of Ag NPs $(P<0.01)$ (Figure 7). In accordance with the present study, Kumar et al. [52] have reported $100 \%$ mortality of $A$. salina at $100 \mathrm{nM}$ concentration of the Ag NPs synthesized by Sargassum ilicifolium. Therefore, the biosynthesized Ag NPs can definitely be used as an ecofriendly antibiofilm agent against marine biofilm forming microorganisms and to prevent further succession. Interestingly, this is the first report on the antimicrofouling activity of the biologically synthesized Ag NPs using T. conoides against marine biofoulers.

\section{Conclusion}

The aqueous extract of seaweed T. conoides can be used as an effective reducing and capping agent for the singlepot biosynthesis of the $\mathrm{Ag}$ and Au NPs. The biologically synthesized Ag NPs with smaller size and outstanding nanostructures are promising materials against the formation of marine biofilms by bacteria and effectively lethal to brine shrimp Artemia salina. Hence, the present study suggests that the biologically synthesized clean, nontoxic, and environmentally acceptable nanoparticles can be applied as coating materials on the surfaces of the aquaculture installations and other marine systems to prevent the settlement and growth of the fouling consortia. Furthermore, in vivo studies are necessary to be carried out on these innovative antifouling strategies to validate the advantages of the synthesized $\mathrm{Ag}$ NPs.

\section{Conflict of Interests}

The authors declare that there is no conflict of interests regarding the publication of this paper.

\section{Acknowledgments}

The authors are thankful to the authorities of Alagappa University and the Department of Physics, Karaikudi, Tamil Nadu, India, for providing necessary facilities and support.

\section{References}

[1] D. M. Yebra, S. Kiil, and K. Dam-Johansen, "Antifouling technology-past, present and future steps towards efficient and environmentally friendly antifouling coatings," Progress in Organic Coatings, vol. 50, no. 2, pp. 75-104, 2004.

[2] G. O’Toole, H. B. Kaplan, and R. Kolter, "Biofilm formation as microbial development," Annual Review of Microbiology, vol. 54, no. 1, pp. 49-79, 2000.

[3] D. G. Davies, M. R. Parsek, J. P. Pearson, B. H. Iglewski, J. W. Costerton, and E. P. Greenberg, "The involvement of cell-to-cell signals in the development of a bacterial biofilm," Science, vol. 280, no. 5361, pp. 295-298, 1998.

[4] P. Stoodley, K. Sauer, D. G. Davies, and J. W. Costerton, "Biofilms as complex differentiated communities," Annual Review of Microbiology, vol. 56, no. 1, pp. 187-209, 2002.

[5] L. Hall-Stoodley, J. W. Costerton, and P. Stoodley, "Bacterial biofilms: from the natural environment to infectious diseases," Nature Reviews of Microbiology, vol. 2, no. 2, pp. 95-108, 2004.

[6] B. Schachter, "Slimy business-the biotechnology of biofilms," Nature Biotechnology, vol. 21, no. 4, pp. 361-365, 2003.

[7] B. Wigglesworth-Cooksey and K. E. Cooksey, "Use of fluorophore-conjugated lectins to study cell-cell interactions in model marine biofilms," Applied and Environmental Microbiology, vol. 71, no. 1, pp. 428-435, 2005.

[8] A. Terlizzi, S. Fraschetti, P. Gianguzza, M. Faimali, and F. Boero, "Environmental impact of antifouling technologies: state of the art and perspectives," Aquatic Conservation, vol. 11, no. 4, pp. 311-317, 2001.

[9] R. A. Braithwaite and L. A. McEvoy, "Marine biofouling on fish farms and its remediation," Advances in Marine Biology, vol. 47, pp. 215-252, 2004.

[10] M. A. Champ, "Economic and environmental impacts on ports and harbors from the convention to ban harmful marine antifouling systems," Marine Pollution Bulletin, vol. 46, no. 8, pp. 935-940, 2003.

[11] C. Anderson, "TBT-free anti-fouling coatings in 2003: for better or for worse?” Corrosion Management, vol. 40, no. 1, pp. 21-24, 2002.

[12] B. S. Smith, "Male characteristics on female mud snails caused by antifouling bottom paints," Journal of Applied Toxicology, vol. 1, no. 1, pp. 22-25, 1981.

[13] T. V. Raveendran and V. P. L. Mol, "Natural product antifoulants," Current Science, vol. 97, no. 4, pp. 508-520, 2009. 
[14] B. A. P. da Gama, R. C. Pereira, A. G. V. Carvalho, and R. Coutinho, "The effects of seaweed secondary metabolites on biofouling," Biofouling, vol. 18, no. 1, pp. 13-20, 2002.

[15] P. Mayavu, S. Sugesh, and V. J. Ravindran, "Antibacterial activity of seagrass species against biofilm forming bacteria," Research Journal of Microbiology, vol. 4, no. 8, pp. 314-319, 2009.

[16] V. P. Limna Mol, T. V. Raveendran, and P. S. Parameswaran, "Antifouling activity exhibited by secondary metabolites of the marine sponge, Haliclona exigua (Kirkpatrick)," International Biodeterioration \& Biodegradation, vol. 63, no. 1, pp. 67-72, 2009.

[17] J. Lellouche, E. Kahana, S. Elias, A. Gedanken, and E. Banin, "Antibiofilm activity of nanosized magnesium fluoride," Biomaterials, vol. 30, no. 30, pp. 5969-5978, 2009.

[18] G. Applerot, J. Lellouche, N. Perkas, Y. Nitzan, A. Gedanken, and E. Banin, "ZnO nanoparticle-coated surfaces inhibit bacterial biofilm formation and increase antibiotic susceptibility," RSC Advances, vol. 2, no. 6, pp. 2314-2321, 2012.

[19] V. Prabhawathi, P. M. Sivakumar, and M. Doble, "Green synthesis of protein stabilized silver nanoparticles using Pseudomonas fluorescens, a marine bacterium, and its biomedical applications when coated on polycaprolactam," Industrial \& Engineering Chemistry Research, vol. 51, no. 14, pp. 5230-5239, 2012.

[20] M. Eshed, J. Lellouche, S. Matalon, A. Gedanken, and E. Banin, "Sonochemical coatings of $\mathrm{ZnO}$ and $\mathrm{CuO}$ nanoparticles inhibit Streptococcus mutans biofilm formation on teeth model," Langmuir, vol. 28, no. 33, pp. 12288-12295, 2012.

[21] M. Rai, A. Yadav, and A. Gade, "Silver nanoparticles as a new generation of antimicrobials," Biotechnology Advances, vol. 27, no. 1, pp. 76-83, 2009.

[22] J. S. Kim, E. Kuk, K. N. Yu et al., "Antimicrobial effects of silver nanoparticles," Nanomedicine, vol. 3, no. 1, pp. 95-101, 2007.

[23] S. Iravani, "Green synthesis of metal nanoparticles using plants," Green Chemistry, vol. 13, no. 10, pp. 2638-2650, 2011.

[24] G. Singaravelu, J. S. Arockiamary, V. G. Kumar, and K. Govindaraju, "A novel extracellular synthesis of monodisperse gold nanoparticles using marine alga, Sargassum wightii Greville," Colloids and Surfaces B, vol. 57, no. 1, pp. 97-101, 2007.

[25] K. Vijayaraghavan, A. Mahadevan, M. Sathishkumar, S. Pavagadhi, and R. Balasubramanian, "Biosynthesis of $\mathrm{Au}(0)$ from $\mathrm{Au}(\mathrm{III})$ via biosorption and bioreduction using brown marine alga Turbinaria conoides," Chemical Engineering Journal, vol. 167, no. 1, pp. 223-227, 2011.

[26] S. Ananthi, H. R. B. Raghavendran, A. G. Sunil, V. Gayathri, G. Ramakrishnan, and H. R. Vasanthi, "In vitro antioxidant and in vivo anti-inflammatory potential of crude polysaccharide from Turbinaria ornata (Marine Brown Alga)," Food and Chemical Toxicology, vol. 48, no. 1, pp. 187-192, 2010.

[27] K. Govindaraju, V. Kiruthiga, V. G. Kumar, and G. Singaravelu, "Extracellular synthesis of silver nanoparticles by a marine alga, Sargassum wightii grevilli and their antibacterial effects," Journal of Nanoscience and Nanotechnology, vol. 9, no. 9, pp. 5497-5501, 2009.

[28] S. Bharathi Raja, J. Suriya, V. Sekar, and R. Rajasekaran, "Biomimetic of silver nanoparticles by Ulva lactuca seaweed and evaluation of its antibacterial activity," International Journal of Pharmacy and Pharmaceutical Science, vol. 4, no. 3, pp. 139143, 2012.

[29] P. Kumar, S. Senthamilselvi, A. Lakshmipraba et al., "Efficacy of bio-synthesized silver nanoparticles using Acanthophora spicifera to encumber biofilm formation," Digest Journal of Nanomaterials and Biostructures, vol. 7, no. 2, pp. 511-522, 2012.
[30] S. Shirley, A. Dayanand, B. Sreedhar, and S. G. Dastager, "Antimicrobial activity of silver nanoparticles synthesized from novel Streptomyces species," Digest Journal of Nanomaterials and Biostructures, vol. 5, no. 2, pp. 447-451, 2010.

[31] J. P. Ruparelia, A. K. Chatterjee, S. P. Duttagupta, and S. Mukherji, "Strain specificity in antimicrobial activity of silver and copper nanoparticles," Acta Biomaterialia, vol. 4, no. 3, pp. 707-716, 2008

[32] C. Nithya, C. Aravindraja, and S. K. Pandian, "Bacillus pumilus of Palk Bay origin inhibits quorum-sensing-mediated virulence factors in gram-negative bacteria," Research in Microbiology, vol. 161, no. 4, pp. 293-304, 2010.

[33] J. Harwig and P. M. Scott, "Brine shrimp (Artemia salina L.) larvae as a screening system for fungal toxins," Applied Microbiology, vol. 21, no. 6, pp. 1011-1016, 1971.

[34] Y. Zhang, J. Mu, J. Han, and X. Gu, "An improved brine shrimp larvae lethality microwell test method," Toxicology Mechanisms and Methods, vol. 22, no. 1, pp. 23-30, 2012.

[35] P. Mulvaney, "Surface plasmon spectroscopy of nanosized metal particles," Langmuir, vol. 12, no. 3, pp. 788-800, 1996.

[36] S. S. Shankar, A. Rai, A. Ahmad, and M. Sastry, "Rapid synthesis of $\mathrm{Au}, \mathrm{Ag}$, and bimetallic Au core-Ag shell nanoparticles using Neem (Azadirachta indica) leaf broth," Journal of Colloid and Interface Science, vol. 275, no. 2, pp. 496-502, 2004.

[37] S. P. Chandran, M. Chaudhary, R. Pasricha, A. Ahmad, and M. Sastry, "Synthesis of gold nanotriangles and silver nanoparticles using Aloe vera plant extract," Biotechnology Progress, vol. 22, no. 2, pp. 577-583, 2006.

[38] D. Philip and C. Unni, "Extracellular biosynthesis of gold and silver nanoparticles using Krishna tulsi (Ocimum sanctum) leaf," Physica E, vol. 43, no. 7, pp. 1318-1322, 2011.

[39] F. Arockiya Aarthi Rajathi, C. Parthiban, V. Ganesh Kumar, and P. Anantharaman, "Biosynthesis of antibacterial gold nanoparticles using brown alga, Stoechospermum marginatum (kützing)," Spectrochimica Acta A, vol. 99, no. 1, pp. 166-173, 2012.

[40] D. Philip, C. Unni, S. A. Aromal, and V. K. Vidhu, "Murraya koenigii leaf-assisted rapid green synthesis of silver and gold nanoparticles," Spectrochimica Acta A, vol. 78, no. 2, pp. 899904, 2011.

[41] I. Sondi and B. Salopek-Sondi, "Silver nanoparticles as antimicrobial agent: a case study on E. coli as a model for gramnegative bacteria," Journal of Colloid and Interface Science, vol. 275, no. 1, pp. 177-182, 2004.

[42] A. Tripathi, N. Chandrasekaran, A. M. Raichur, and A. M. Mukherjee, "Antibacterial applications of silver nanoparticles synthesized by aqueous extract of Azadirachta Indica (Neem) leaves," Journal of Biomedical Nanotechnology, vol. 5, no. 1, pp. 93-98, 2009.

[43] M. Gnanadesigan, M. Anand, S. Ravikumar et al., "Antibacterial potential of biosynthesized silver nanoparticles using Avicennia marina mangrove plant," Applied Nanoscience, vol. 2, no. 2, pp. 143-147, 2011.

[44] K. Kathiresan, N. M. Alikunhi, S. Pathmanaban, A. Nabikhan, and S. Kandasamy, "Analysis of antimicrobial silver nanoparticles synthesized by coastal strains of Escherichia coli and Aspergillus niger," Canadian Journal of Microbiology, vol. 56, no. 12, pp. 1050-1059, 2010.

[45] F. Martinez-Gutierrez, L. Boegli, A. Agostinho et al., "Antibiofilm activity of silver nanoparticles against different microorganisms," Biofouling, vol. 29, no. 6, pp. 651-660, 2013. 
[46] R. Thenmozhi, P. Nithyanand, J. Rathna, and S. K. Pandian, "Antibiofilm activity of coral-associated bacteria against different clinical M serotypes of Streptococcus pyogenes," FEMS Immunology \& Medical Microbiology, vol. 57, no. 3, pp. 284-294, 2009.

[47] S. Gowrishankar, N. D. Mosioma, and S. K. Pandian, "Coralassociated bacteria as a promising antibiofilm agent against methicilin-resistant and susceptible Staphylococcus aureus biofilms," Evidence-Based Complementary and Alternative Medicine, vol. 2012, Article ID 862374, 16 pages, 2012.

[48] D. Bakkiyaraj and S. K. Pandian, "In vitro and in vivo antibiofilm activity of a coral associated actinomycete against drug resistant Staphylococcus aureus biofilms," Biofouling, vol. 26, no. 6, pp. 711-717, 2010.

[49] S. A. Abu Sayem, E. Manzo, L. Ciavatta et al., "Anti-biofilm activity of an exopolysaccharide from a sponge-associated strain of Bacillus licheniformis," Microbial Cell Factories, vol. 10, article 74, pp. 1-12, 2011.

[50] J. B. Kaplan, C. Ragunath, K. Velliyagounder, D. H. Fine, and N. Ramasubbu, "Enzymatic detachment of Staphylococcus epidermidis biofilms," Antimicrobial Agents and Chemotherapy, vol. 48, no. 7, pp. 2633-2636, 2004.

[51] J. R. Mireles II, A. Toguchi, and R. M. Harshey, "Salmonella enterica serovar typhimurium swarming mutants with altered biofilm-forming abilities: surfactin inhibits biofilm formation," Journal of Bacteriology, vol. 183, no. 20, pp. 5848-5854, 2001.

[52] P. Kumar, S. S. Selvi, A. L. Praba et al., "Antibacterial activity and in-vitro cytotoxicity assay against brine shrimp using silver nanoparticles synthesized from Sargassum ilicifolium," Digest Journal of Nanomaterials and Biostructures, vol. 7, no. 4, pp. 1447-1455, 2012. 

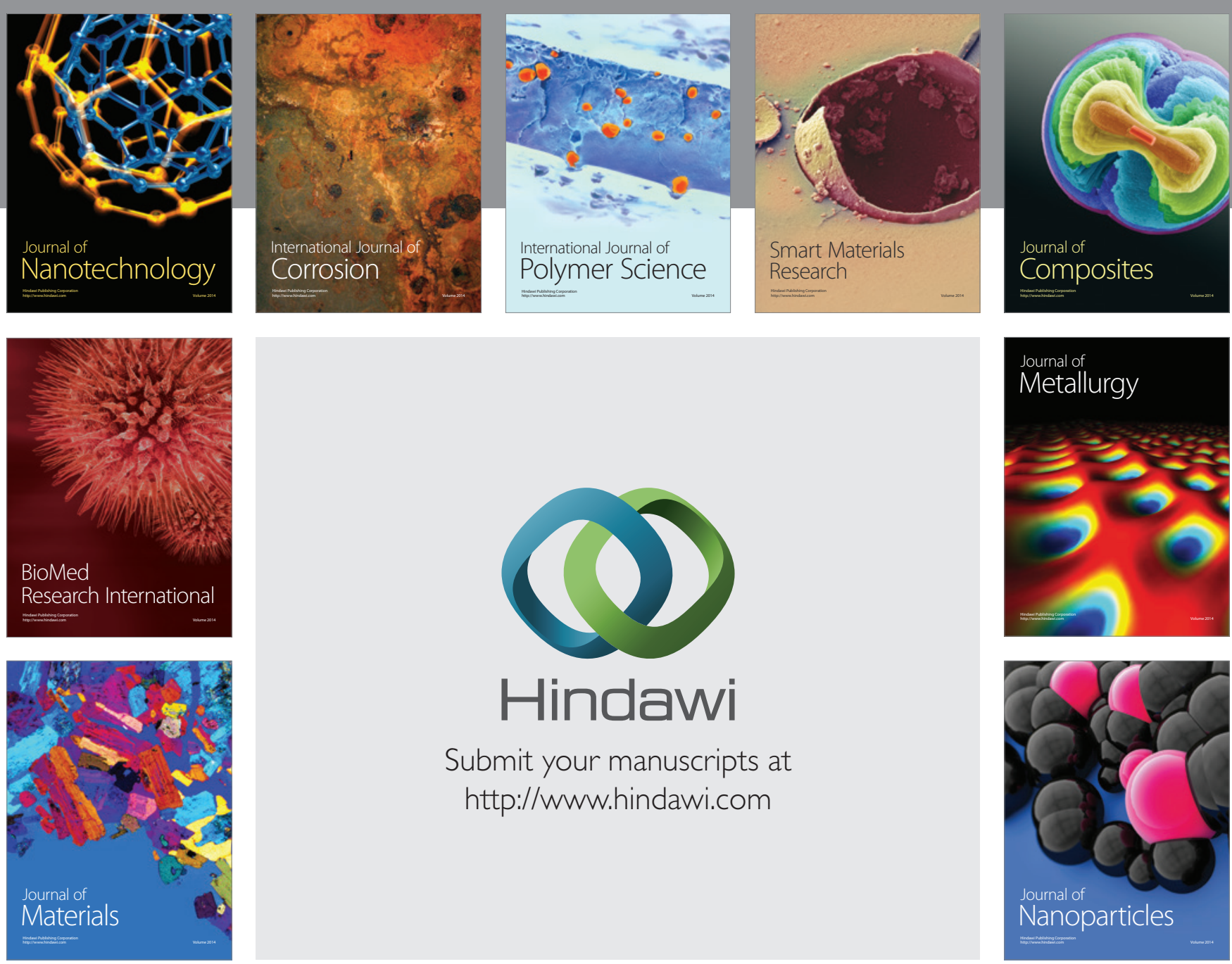

Submit your manuscripts at http://www.hindawi.com
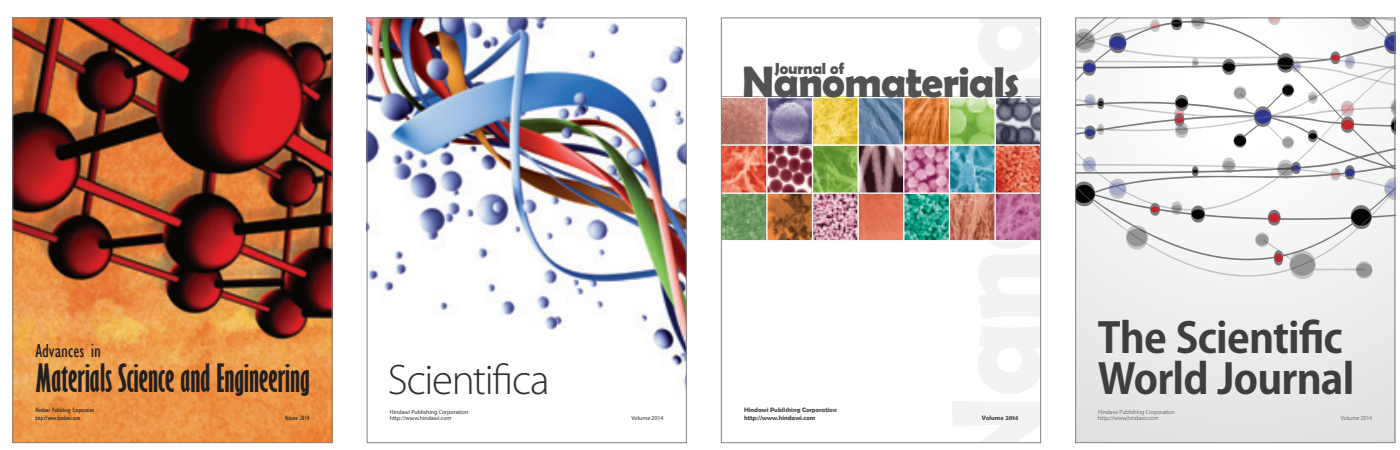

\section{The Scientific World Journal}
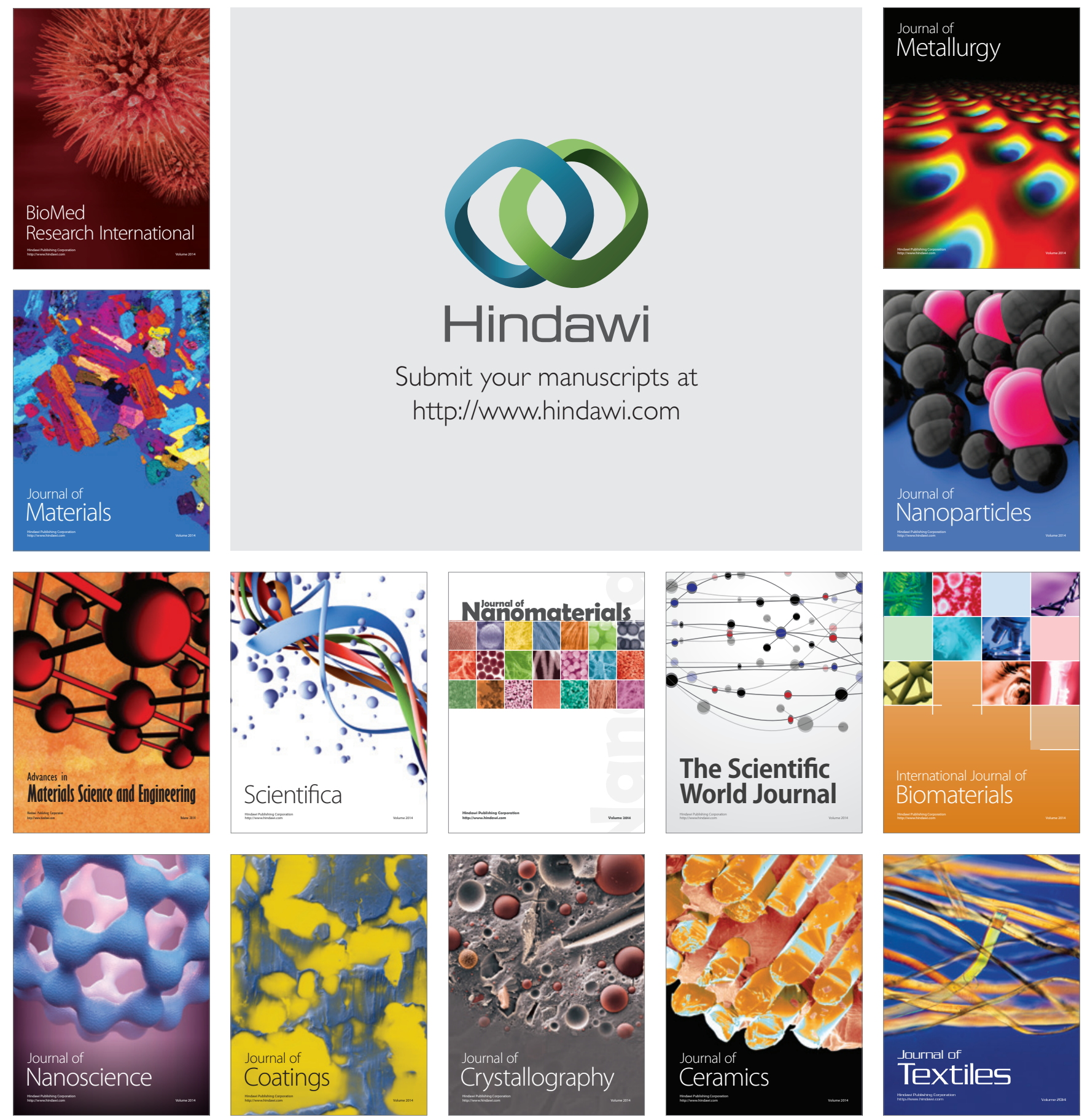